\title{
Process assessment associated to microbial community response provides insight on possible mechanism of waste activated sludge digestion under typical chemical pretreatments
}

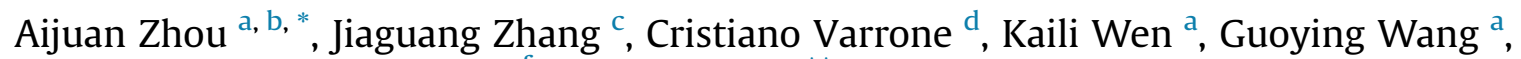 \\ Wenzong Liu ${ }^{\mathrm{e}}$, Aijie Wang ${ }^{\mathrm{e}, \mathrm{f}}$, Xiuping Yue ${ }^{\mathrm{a}, * *}$ \\ ${ }^{a}$ College of Environmental Science and Engineering, Taiyuan University of Technology, Taiyuan 030024, China \\ ${ }^{\mathrm{b}}$ State Key Laboratory Breeding Base of Coal Science and Technology Co-founded by Shanxi Province and the Ministry of Science and Technology, Taiyuan \\ University of Technology, Taiyuan 030024, China \\ ${ }^{c}$ College of Architecture and Civil Engineering, Taiyuan University of Technology, Taiyuan 030024, China \\ d Department of Chemical and Biochemical Engineering, Technical University of Denmark, Denmark \\ ${ }^{\text {e }}$ Research Center for Eco-Environmental Sciences, Chinese Academy of Sciences, Beijing 100085, China \\ ${ }^{\mathrm{f}}$ State Key Laboratory of Urban Water Resource and Environment, Harbin Institute of Technology (SKLUWRE, HIT), Harbin 150090, China
}

\section{A R T I C L E I N F O}

\section{Article history:}

Received 24 July 2016

Received in revised form

10 February 2017

Accepted 14 February 2017

Available online 1 March 2017

\section{Keywords:}

Waste activated sludge (WAS)

Chemical pretreatments

Anaerobic digestion

Pyrosequencing

Microbial community

\begin{abstract}
A B S T R A C T
Current studies have employed various chemicals for disintegrating and hydrolyzing microbial cells in waste activated sludge (WAS). However, a comprehensive process assessment over the whole anaerobic digestion process has seldom been proposed. Besides, the characterization of microbial community responses to these chemicals is not well understood. In this study, the effects of five typical chemicals: solubilizer ( $\beta$-cyclodextrin, $\mathrm{CD}$ ), alkaline $(\mathrm{NaOH})$, peroxide (peracetic-acid, $\mathrm{PA})$, biological (rhamnolipid, $\mathrm{RL}$ ) and chemical (sodium dodecylsulphate, SDS) surfactants on WAS digestion were examined. Higher efficiencies of WAS solubilization, hydrolysis and acidification were achieved by CD treatment, followed by RL and SDS. Methanogenesis was also strongly chemicals-dependent. Shifts in microbial community structure were observed in all chemical-pretreated WAS. The community in RL, CD and PA was dominated by microorganisms that anaerobically hydrolyze organics to acids, while that in $\mathrm{NaOH}$ and SDS was mainly associated to biogas production. This study proved that the overall performance of WAS digestion was substantially depended on the initial chemical pretreatments, which in turn influenced and was related to the microbial community structures. Although the economic advantage might not be clear yet, the findings obtained in this work may provide a scientific basis for the potential implementation of chemicals for WAS treatment.
\end{abstract}

() 2017 Elsevier Ltd. All rights reserved.

\section{Introduction}

Due to the widely used activated sludge processes for wastewater treatment, the disposal and treatment of waste activated sludge (WAS) has become an issue of particular concern. As the byproduct of wastewater treatment plants (WWTPs), about 7.00

\footnotetext{
* Corresponding author. College of Environmental Science and Engineering, Taiyuan University of Technology, Taiyuan 030024, Shanxi Province, China.

** Corresponding author. College of Environmental Science and Engineering, Taiyuan University of Technology, Taiyuan 030024, Shanxi Province, China.

E-mail addresses: zhouaijuan@tyut.edu.cn (A. Zhou), yuexiuping@tyut.edu.cn (X. Yue).
}

million tons dry sludge has been produced in China in 2015 (Urban Statistics Yearbook of China (2015)), and is still showing a rapid increasing rate. The main means to deal with WAS in China were land application ( $45 \%)$, landfill ( $30 \%)$, incineration ( $5 \%)$, plus approximately $15 \%$ without any treatment. The rapid increasing energy demand, along with growing concerns for environmental protection, has suggested the use of WAS recycling as alternative energy source [1]. Cost-effective microbial conversion to valuable products by anaerobic digestion is acknowledged as the most costeffective way for WAS treatment and the concomitant generation of bioenergy resources, where hydrolysis is known as the ratelimiting step [2]. As the organic compounds in WAS are mainly organized in the form of microbial cells, pretreatment is thus a 
prerequisite, in order to keep operations within an industrially acceptable time-frame. Aiming to strengthen the performance of WAS digestion, many approaches involving physical, chemical or biological methods have therefore been developed [2].

Chemical pretreatments employ different chemical reagents for disintegrating and hydrolyzing the cell wall and membrane, thus increase the solubility of the organic matter contained within the cells. In the past, various chemical methods have been developed, based on different operating principles. Alkaline treatment has been selected as a potential way for enhancing WAS acidification [3] and methanogenesis [4]. Nowadays, surfactants are also regarded as an alternative strategy for WAS pretreatment, due to their unique characteristics. Jiang et al., for instance, investigated the effect of chemically synthetic surfactants, sodium dodecylsulphate (SDS), on volatile fatty acids (VFAs) production from WAS fermentation [5]. Our previous studies showed the feasibility of VFAs and methane production from WAS by a pretreatment of microbial- (rhamnolipid) and plant- (saponin) derived biosurfactants [6,7]. Several oxidants, such as ozone, hydrogen peroxide, peroxidation and chlorine dioxide, have been applied to break down WAS. Such advanced oxidation processes are based on the generation of hydroxyl radicals, which are extremely powerful oxidants [2]. Yang et al. [8] also used $\beta$-cyclodextrin (CD) as a pretreatment for improving the VFAs production from WAS [8]. As a typical solubilizer, $C D$ and its derivatives can rupture a cell's membrane, releasing intracellular substances into the water. WAS solubilization was clearly enhanced by these methods, nevertheless, only few studies have combined said pretreatments with the whole anaerobic digestion process, including hydrolysis, acidification and methanogenesis.

Besides, how and why the numerous chemical pretreatments were capable of enhancing the WAS digestion efficiency, the evaluation of suitable methods to achieve different objectives, i.e., biogas production, biological nutrient removal or biopolymer production, have seldom been proposed for the operation of WWTPs. Currently, one of the main problems in WWTPs is to obtain stable and highly efficient biological removal of nutrients. In China, an unfavorable ratio of organic carbon compounds (particularly some easily biodegradable VFAs) to nitrogen (N) and phosphorus ( $\mathrm{P}$ ) compounds in influent wastewater often becomes a problem to guarantee efficient denitrification and biological phosphorus removal. One of the simplest method to solve this problem is to add commercially available organic compounds (i.e. methanol, ethanol, HAc) to increase the COD/TN or COD/TP ratios [9]. However, these processes generate additional operational costs and can be difficult to apply in practical WWTPs. Typically, WAS is carbonaceous in nature and rich in organic carbon, thus, some researchers have reported that disintegrated WAS [10] or return activated sludge [11] could be regarded as an available biodegradable carbon source. Fermentation-elutriation has been widely applied to produce VFAs from sludge, the spectrum of acids in fermented sludge is suitable for biological nitrogen and phosphorus removal [12]. More commonly, many researches have focused on converting WAS to biogas $[1,13,14]$ or hydrogen [15]. There is also potential to use sludge fermentation liquid, sludge reject water and digested WAS as substrates for mixed-culture polyhydroxyalkanoates (PHAs) biopolymer production [16]. There is clearly an important ongoing debate about these various chemical pretreatments for WAS, concerning which one would be more conducive to produce VFAs, rather than PHAs biopolymer or methane. It can be thus speculated that, arbitrarily selecting any one of these chemical pretreatments, without a careful comparison, might not achieve the aim of WAS cost-efficient treatment and high-efficient bioresource \& bioenergy recovery.

It is well known that most of the organic matter in WAS is embedded in its cells and extracellular polymer matrix. Before bacteria can assimilate high molecular weight compounds, the compounds are usually hydrolyzed by extracellular enzymes [17]. Characterization of dissolved organic matter (DOM) would be useful for understanding the WAS destruction mechanisms after pretreatment. Excitation-emission matrix (EEM) fluorescence spectroscopy, coupled with parallel factor analysis (PARAFAC), is an established tool for organic matter fingerprinting in aqueous systems [18]. The resulting EEM provides the fluorescence characteristics of samples over the range of excitation and emission wavelengths scanned simultaneously, without destruction the samples. Therefore, based on the above-mentioned considerations, we investigated and compared the effect of five widely used chemicals: $\beta$-cyclodextrin (solubilizer), $\mathrm{NaOH}$ (alkaline), peraceticacid (peroxide), rhamnolipid (biological surfactant) and sodium dodecylsulphate (chemical surfactant) on WAS digestion, including hydrolysis, acidification and methanogenesis. We monitored particulate organic matter solubilization and hydrolytic enzyme activities in this study. The different fractions of DOM from the sludge flocks (before and after treatments) were characterized using EEM fluorescence spectroscopy with PARAFAC analysis. Furthermore, multiple groups of microorganisms were generally involved in the anaerobic digestion of WAS [15]. Understanding microbial behavior and interactions is essential to improve the anaerobic treatment process $[19,20]$. Therefore, we examined the microbial community structure using high-throughput pyrosequencing of the 16S rRNA gene, which can provide important information to better understand the microbial response mechanism to the five chemicaltreated WASs. Correlations between environmental variables and microbial populations were assessed, using canonical correspondence analysis (CCA).

\section{Material and methods}

\subsection{Source and pretreatment of waste activated sludge}

WAS was collected from Wenchang municipal wastewater treatment plant (Harbin City, China) and concentrated by settling at $4{ }^{\circ} \mathrm{C}$ for $24 \mathrm{~h}$, prior to tests. Its characteristics (average value, plus standard deviation of triplicates) were as follows: pH $6.32 \pm 0.15$, total suspended solids (TSS) $22663 \pm 479 \mathrm{mg} / \mathrm{L}$, volatile suspended solids (VSS) $14000 \pm 219 \mathrm{mg} / \mathrm{L}$, TCOD (total chemical oxygen demand) $20018 \pm 302 \mathrm{mg} / \mathrm{L}$, SCOD (soluble chemical oxygen demand) $477 \pm 51 \mathrm{mg} / \mathrm{L}$, total protein $11690 \pm 202 \mathrm{mg} \mathrm{COD} / \mathrm{L}$, solute protein $191 \pm 23 \mathrm{mg}$ COD/L, total carbohydrate $1614 \pm 79 \mathrm{mg}$ COD/L, solute carbohydrate $12 \pm 2 \mathrm{mg} \mathrm{COD} / \mathrm{L}$ and VFAs $99 \pm 12 \mathrm{mg}$ COD/L. The specific dosages of five typical chemicals ( $\beta$-cyclodextrin $(C D)$, $\mathrm{NaOH}$, peracetic-acid (PA), rhamnolipid (RL) and SDS) are reported in Table 1.

\subsection{Semi-continuous flow experimental setup and operations}

WAS digestion was conducted in a series of continuous stirred tank reactors (CSTRs) (Supporting information (SI), Fig. S1). The

Table 1

Dosages of chemicals for WAS pretreatment.

\begin{tabular}{llll}
\hline Group & Chemicals & Dosages & References \\
\hline 1 & CD & $0.3 \mathrm{~g} / \mathrm{g}$ VSS & {$[8]$} \\
2 & $\mathrm{NaOH}$ & Initial pH 10 & {$[3]$} \\
3 & $\mathrm{PA}$ & $0.1 \mathrm{~g} / \mathrm{g} \mathrm{VSS}$ & {$[31]$} \\
4 & $\mathrm{RL}$ & $0.04 \mathrm{~g} / \mathrm{g}$ VSS & {$[6]$} \\
5 & SDS & $0.1 \mathrm{~g} / \mathrm{g}$ VSS & {$[5]$} \\
6 & None & the control & - \\
\hline
\end{tabular}


reactor consisted of two Plexiglas cylinders $(120 \mathrm{~mm}$ and $160 \mathrm{~mm}$ diameters): the inner cylinder, with a volume of $3.0 \mathrm{~L}$ and a headspace of $1.0 \mathrm{~L}$, was used for fermentation. The temperature of $35 \pm 2{ }^{\circ} \mathrm{C}$ was maintained by circulating water from a water bath heating vessel. The mixing was carried out by a controlled electric stirrer $(100 \mathrm{rpm})$. The reactors were initially seeded with the pretreated WASs. During the first 10 days fermentation, the reactor was operated in batch mode without feeding (Phase 1, from day 1 to day 10). From day 11 afterward, the reactor was fed with fresh substrate, with sludge sampling just before feeding (Phase 2, from day 11 to day 30). Each reactor was operated with the same hydraulic retention time of $10 \mathrm{~d}$. In order to minimize $\mathrm{pH}$ fluctuations within the digesters, the reactors were fed twice a day. All the fermentation experiments were carried out in triplicate.

\subsection{DNA extraction and pyrosequencing}

Before DNA extraction, sludge samples were centrifuged at $8000 \mathrm{~g}$ to remove supernatant. DNA was extracted from sludge sediments of three replicate reactors using Soil DNA Isolation Kit (Sangon Biotech Co., Ltd.), according to the manufacturer's instructions, and then pooled together. Amplicon liberates were constructed for pyrosequencing, using bacterial fused primers $341 \mathrm{~F}$ and 805R for the V3-V4 region of the 16S rRNA gene. Archaeal primers were $344 \mathrm{~F}$ and $915 \mathrm{R}$. To achieve the sample multiplexing during pyrosequencing, barcodes were incorporated between the adaptor and forward primer. The procedure of Polymerase chain reaction (PCR) reactions was performed in our previous study [21]. After being purified and quantified, the PCR amplicon was used for pyrosequencing on an Illumina MiSeq. The raw sequences were deposited in the NCBI Short Read Archive database with the accession no. SRR3087264. The adapters, barcodes, and primers in all raw sequences were trimmed to minimize the effects of random sequencing errors. Sequences shorter than $350 \mathrm{bp}$, or containing any ambiguous base calls, were removed.

The remaining sequences were clustered into operational taxonomic units (OTUs), using the 97\% identity threshold (3\% dissimilarity level). Alpha diversity measurements, including Shannon, abundance-based coverage estimator (ACE) and Chao1 indices were calculated for each sample. Beta diversity was calculated by means of the distance matrices generated using the phylogenetic-based method UniFrac [22] and then visualized, using principal coordinates analysis (PCOA). Finally, OTUs networks were visualized in Cytoscape v3.2.1 for depicting the similarity and difference between the different sludge fermentation systems [23]. CCA analysis were conducted by Canoco 4.5 to examine correlations between characteristic genera and the environmental and performance measurements, including $\mathrm{pH}$, methane production, hydrolytic enzymes ( $\alpha$-glucosidase and protease), VFA, soluble proteins and carbohydrates concentrations. Relative abundance of 12 characteristic bacterial and 6 archaeal genera was used in the CCA analysis.

\subsection{Analytical methods}

WAS samples were centrifuged at $10000 \mathrm{~g}$ for $10 \mathrm{~min}$ and filtered through a $0.45 \mu \mathrm{m}$ cellulose nitrate membrane filter and stored at $4{ }^{\circ} \mathrm{C}$, prior to analysis. The determinations of SCOD, TCOD, TSS, and VSS were conducted according to standard methods [24]. The $\mathrm{pH}$ value was measured by a $\mathrm{pH}$ meter (Seven Multi, Mettler Toledo, Switzerland). According to a previous study, carbohydrates and proteins were measured by the phenol-sulfuric and bicinchoninic acid methods with glucose and bull serum albumin as the standards, respectively [7]. An Agilent 7890 gas chromatograph (GC), equipped with a flame ionization detector (FID), was utilized to analyze the composition of the VFAs. The VFAs production was calculated as the sum of the measured acetic (HAc), propionic (HPr), n-butyric (n-HBu), iso-butyric (iso-HBu), n-valeric (n-HVa) and iso-valeric (iso-HVa) acids. The COD conversion factors are $1.50 \mathrm{~g}$ COD/g protein (assumed as $\left.\left(\mathrm{C}_{4} \mathrm{H}_{6.1} \mathrm{O}_{1.2} \mathrm{~N}\right) \mathrm{x}\right), 1.06 \mathrm{~g} \mathrm{COD} / \mathrm{g}$ carbohydrate (assumed as $\mathrm{C}_{6} \mathrm{H}_{12} \mathrm{O}_{6}$ ), $1.07 \mathrm{~g} \mathrm{COD} / \mathrm{g} \mathrm{HAc}, 1.51 \mathrm{~g} \mathrm{COD} / \mathrm{g}$ $\mathrm{HPr}, 1.82 \mathrm{~g} \mathrm{COD} / \mathrm{g} \mathrm{HBu}$, and $2.04 \mathrm{~g} \mathrm{COD} / \mathrm{g}$ HVa. Gas composition was analyzed using another GC (4890D, Agilent), equipped with a thermal conductivity detector (TCD).

The detailed ultrasound protocol for extracellular polymeric substances (EPS) extraction of WAS samples is provided in the SI. The activity of $\alpha$-glucosidase and protease was measured according to Goel et al. [25], and the detailed description of procedure is reported in the SI. Fluorescence excitation-emission matrix (EEM) was measured using a fluorescence spectrometry (FP-6500, Jasco, Tokyo, Japan). Parallel factor analysis (PARAFAC) was used to model EEM fluorescence data in this study. The protocol is detailed in the SI.

\section{Results and discussion}

\subsection{Effect of chemical pretreatments on WAS solubilization}

WAS solubilization is generally recognized as a critical step before hydrolysis. As proteins and carbohydrates are the main constituents of WAS, accounting for $58 \%$ and $8 \%$ of TCOD, thereby, the solubilization of organics can be expressed by that of proteins and carbohydrates in different WAS layers (DOM, loosely-bound EPS (LB-EPS) and tightly-bound EPS (TB-EPS)). Fig. 1 illustrates that all five chemical pretreatments had a positive effect on the solubilization of particulate organic matter from sludge flocks at $24 \mathrm{~h}$, but their extent varied. Marked rises for proteins and carbohydrates in DOM were observed after pretreatments, particularly in the case of CD $(1759 \pm 89$ and $301 \pm 28 \mathrm{mg} C O D / L$, respectively $)$, with an increase of up to 1.1-2.7 and 1.2-1.9-times compared with the other four pretreatments. On the other hand, proteins and carbohydrates dropped in the TB-EPS layer, compared to the raw WAS, decreasing to $461 \pm 14,459 \pm 16$ and $303 \pm 37 \mathrm{mg}$ proteins/L (as COD) in CD, RL and SDS, respectively (Fig. 1A); an analogous trend was observed in the case of carbohydrates (Fig. 1B). In other words, solubilizer (CD) and surfactants (RL and SDS) clearly promoted solubilization performance with respect to the increase of soluble organics in liquid and the detaching in TB-EPS. Interestingly, the amounts of organics in LB-EPS was somewhat increased by pretreatments, instead of decreasing. The reason was presumably that the LB-EPS layer was characterized by loose structure and rheological property, which easily adsorbed the intracellular and TB-EPS-released organics.

These result were further supported by EEM profiles. As shown in Fig. 1C, EEM fluorescence spectra, in terms of DOM obtained under the five pretreatments at $24 \mathrm{~h}$, were similar in the peak locations, but had different fluorescence intensities (FI). By separating the spectra of the main components from overlapped EEM spectra, four components were found to be appropriate for PARAFAC analysis. The specific components were identified as tryptophan-like (Ex/Em 270/350, Com.1), tyrosine-like (Ex/Em 270/ 300, Com.2), humic-acid-like substances (Com.3, Ex/Em 320/410) and fulvic-like substrates (Ex/Em 280/440, Com.4) (Fig. S2) [26,27]. The intensities of DOM were clearly enhanced by the pretreatments. Tyrosine-like protein substance was the primary component with surfactant (RL and SDS) treatments, with a FI of 579 and 365 , compared to only 95 of the control. Conversely, tryptophan-like substance was the dominant component in $C D$, $\mathrm{NaOH}$ and PA, with the FIs peaking at 401, 129 and 108. A similar phenomenon was also observed by other pretreatments, such as 

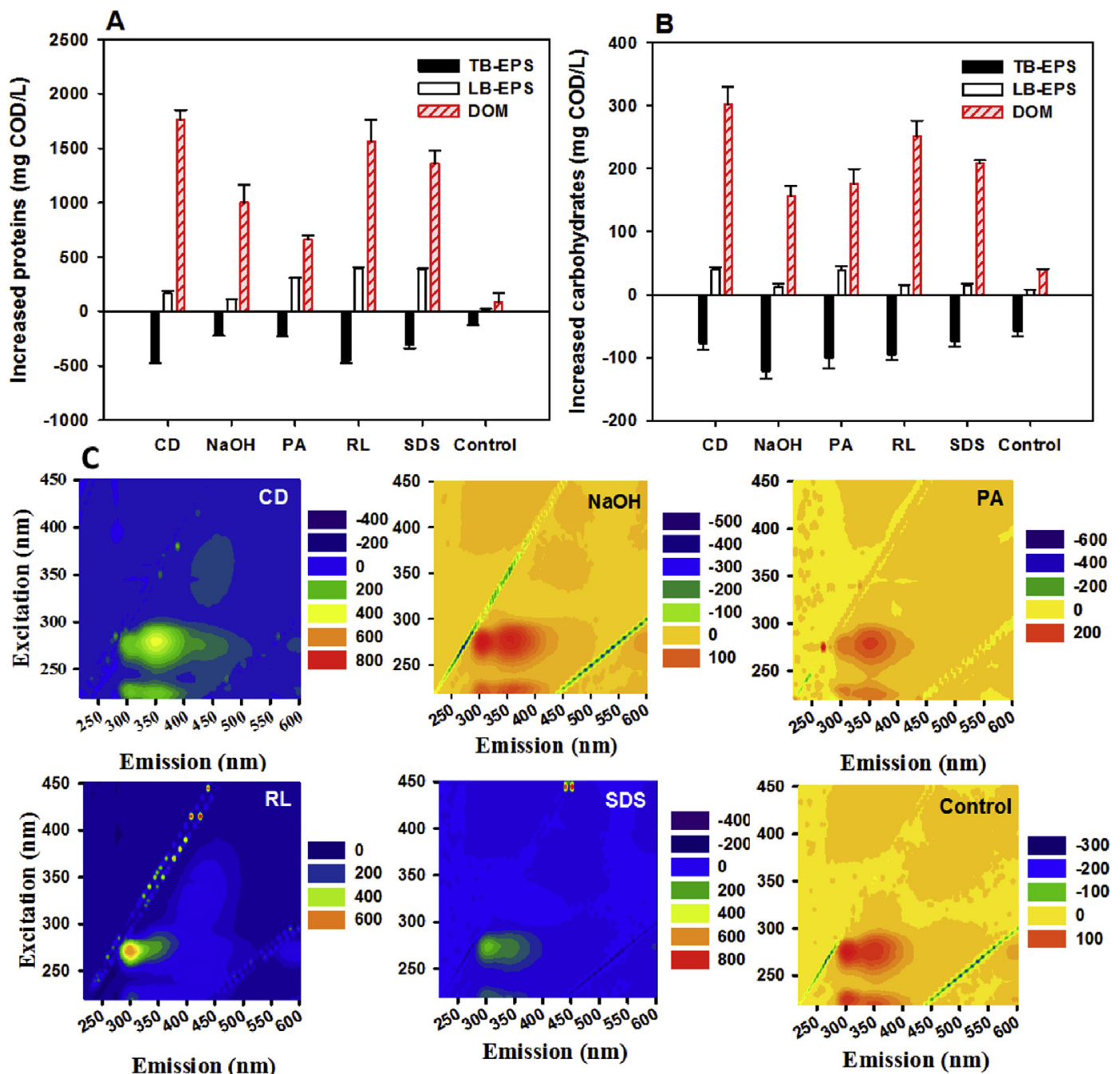

Emission (nm)

Emission (nm)
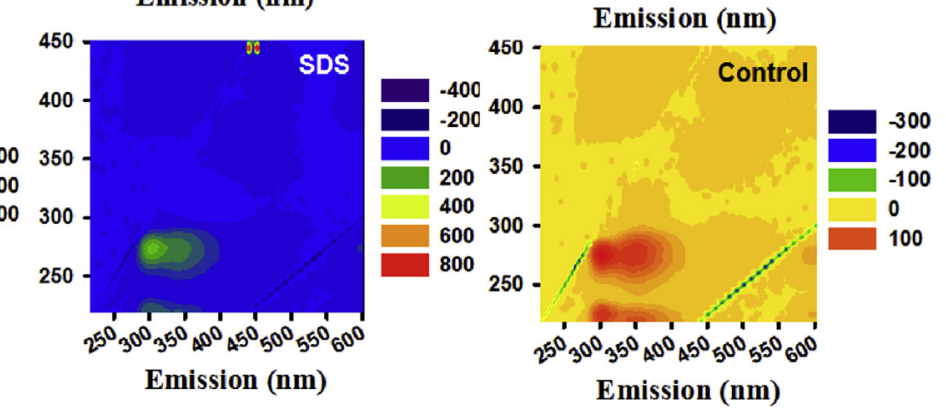

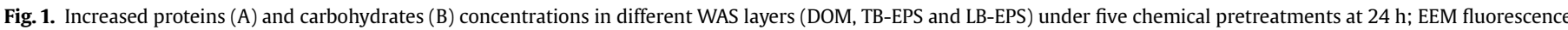
spectra of DOM from the five pretreated WAS, amended by subtracting the spectra of raw WAS (C) (Note: error bars represent standard deviation).

enzymatic [28], high-pressure homogenization [29], and free nitrous acid [30] treatments. This underlines the significance of the treatments in dissolving the proteins, which are inside the microbial cell wall or enmeshed in EPS, into the liquid phase. All the facts revealed that solubilizer and surfactants caused a severer disruption of sludge flocks than alkaline and peroxide, which was consistent with the data presented in Fig. 1A. Small amounts of humic- and fulvic-acid-like substances were found in DOM fluorescence spectra, which were mainly formed by the microbial degradation of dead organic matter.

\subsection{Effect of chemical pretreatments on WAS hydrolysis, acidification and methanogenesis}

The time-course profiles of soluble carbohydrates and proteins concentrations in CSTR are shown in Figs. S3A and B. A large amount of soluble organics was observed in WAS solution. The accumulation of soluble organics in DOM depends on the rates of production and consumption. Production is achieved mainly through solubilization and hydrolysis of particulate organic matter, which is mainly aggregated in EPSs and embedded in the intracellular substances in microbial cells. Consumption is achieved by biodegradation such as acidification and methanogenesis. During the batch operation (Phase 1), these soluble organic compounds were rapidly consumed (during the first 2 days of operation) in conjunction with VFAs production, and then stabilized at different levels with negligible variations until the end of the run. The stabilized soluble proteins were estimated to be around 1215, 1318, 1269, 1111 and $899 \mathrm{mg}$ COD/L in CD, RL, SDS, PA, NaOH, and the corresponding value for carbohydrates were 210, 234, 224, 178 and $143 \mathrm{mg} \mathrm{COD} / \mathrm{L}$. Soluble proteins and carbohydrate in the Control were only 948 and $113 \mathrm{mg}$ COD/L, respectively. This confirmed that chemical pretreatments, especially for $\mathrm{CD}, \mathrm{RL}$ and SDS, enhanced the efficiency of WAS hydrolysis. Since proteins and carbohydrates represented the major organic fraction of WAS, the activities of $\alpha$ glucosidase and protease were quite important in the hydrolysis process (Fig. 2C). The results showed that the two enzymes were clearly active after pretreatments. Taking CD treatment as example, the activities of protease and $\alpha$-glucosidase were $224 \pm 15$ and $114 \pm 11 \mathrm{Eu}$, which enabled a 5.2-fold and 6.7-fold increase over that in the control. Similar observations were also reported by Jiang et al. (2007) for SDS treatment [5].

Supposing that the production rate of soluble organics equaled that of consumption during Phase 1, the highest consumed carbohydrates and proteins were obtained with CD (559 and $94 \mathrm{mg}$ COD/ $\mathrm{L}$ ), then higher in $\mathrm{RL}$ (317 and $46 \mathrm{mg} \mathrm{COD} / \mathrm{L}$ ) and SDS (221 and 

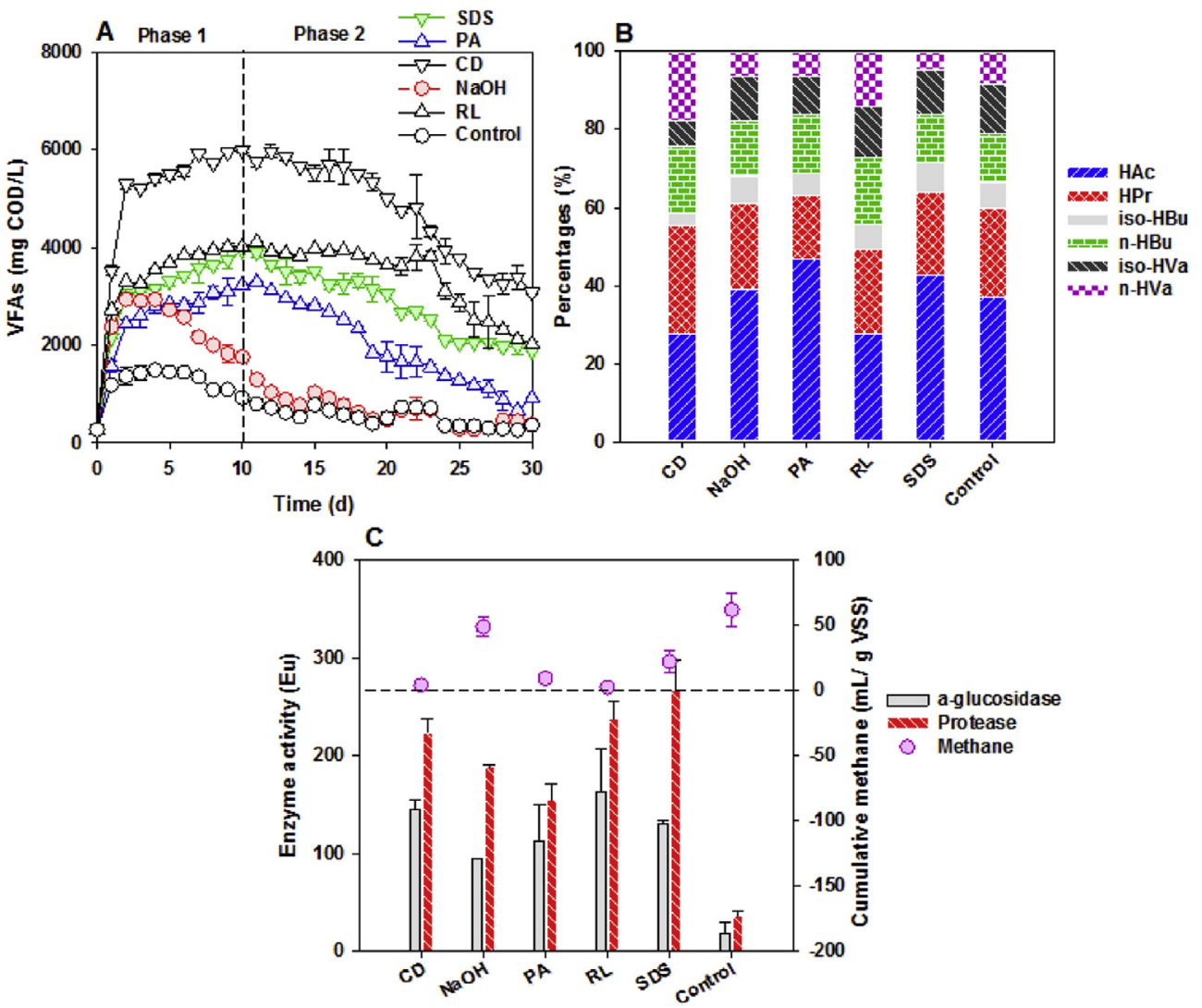

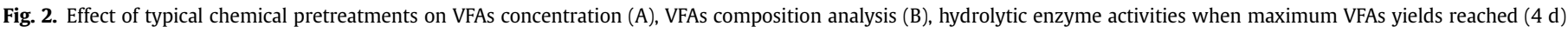
and cumulative methane production (10 d) (C) (Note: error bars represent standard deviation).

$26 \mathrm{mg} \mathrm{COD} / \mathrm{L})$. Because VFAs were produced from protein and carbohydrate biodegradation by acidogenic bacteria, similar trends were observed in both of them. The corresponding VFAs concentrations rapidly increased from the begging, and then gradually decreased in $\mathrm{NaOH}$ and Control tests, while it stabilized in $\mathrm{CD}, \mathrm{PA}$, RL and SDS with time extension (Fig. 2A). It peaked with $5408 \pm 93$, $3540 \pm 17,3164 \pm 36,2935 \pm 85,2789 \pm 122$ and $1491 \pm 55 \mathrm{mg}$ COD/ $\mathrm{L}$ in $\mathrm{CD}, \mathrm{RL}, \mathrm{SDS}, \mathrm{PA}, \mathrm{NaOH}$ and Control tests on day 4, respectively. The solubilizer and surfactants treated tests led to an expected increase in VFAs yield over the alkaline and peroxide treated tests. On the other hand, VFAs produced under different chemical pretreatments were diverse in composition (Fig. 2B). HAc formed the major part of total VFAs in almost all tests (except in CD) and varied from $28 \%$ (RL) to $47 \%$ (PA). This was in accordance with previous studies $[3,5,6,31]$. HPr and n-HBu represented the second and third most abundant metabolites, with percentages around $21 \%$ and $14 \%$. These results seemed to be in agreement with Wang et al. [32] which showed that the top two VFAs were HAc and HPr, no matter which type of sludge pretreatment method was used (ultrasonic, thermal and freezing) [32]. On the contrary, $\operatorname{HPr}(28 \%), \mathrm{HAc}$ (27\%) and n-HVa (18\%) were the most abundant VFAs in the case of $\mathrm{CD}$. This would suggest that the treatment methods can not only affect the acidification efficiency, but indeed, influence the acidification product spectrum as well.

As depicted in Fig. 2C, methane production was also strongly pretreatment-dependent. Final cumulative methane yield on day 10 was about $62 \pm 13 \mathrm{~mL} / \mathrm{g}$ VSS in the control, followed by $49 \pm 7$ and $22 \pm 8 \mathrm{~mL} / \mathrm{g}$ VSS in $\mathrm{NaOH}$ and SDS. It was clearly inhibited by $\mathrm{CD}, \mathrm{PA}$ and RL treatments. Jiang et al. [5] found that with SDS dosage increasing from 0.02 to $0.3 \mathrm{~g} / \mathrm{g}$, the inhibition rate of methane production increased sharply from 3 to $100 \%$. In the presence of $0.1 \mathrm{~g}$ SDS/g WAS (VSS), the inhibition rate reached up to about $50 \%$, thereby the lower methane yield, compared with that of $\mathrm{NaOH}$. Our previous study, as well as Huang et al. [33], showed that RL could totally inhibit the methanogenesis [6,33]. Appels et al. [31] concluded that applying high PA dosages (80-100 g/kg DS) leads to a significantly lower biogas production. The $\mathrm{pH}$ reduction resulted by the high concentration of VFAs could be the reason of low methanogenesis efficiency. It was well known that methanogenesis is strongly $\mathrm{pH}$-dependent and most methanogenic bacteria function in a $\mathrm{pH}$ range of 6.5-7.2, with an optimum $\mathrm{pH}$ near 7.0 [34]. In this study, we have studied the $\mathrm{pH}$ evolution in the presence of the five chemical pretreatments. As shown in Fig. S3C, the pH values of CD, PA, RL and SDS tests (group I) on the 10th day were all indeed below the optimum range (5.4, 5.9, 6.1 and 6.3), as a result of the above-mentioned high concentration of VFAs. On the other hand, $\mathrm{pH}$ was in the optimum range in the case of $\mathrm{NaOH}$ and Control (7.1 and 6.7), which was consistent with their enhanced biogas yield. Concerning the continuous operation (Phase 2), VFAs production, soluble carbohydrates and proteins first stabilized, and then were biodegraded to methane (Figs. S3A and B and Fig. 2A). The time-course profiles of individual VFAs are shown in Fig. S4.

Usually, hydrolysis, acidification and methanogenesis all occur in sludge digestion processes. VFAs, the products of acidification, are the substrate for methanogenesis and can be easily metabolized by methanogens. In this sense, the observation in this study was remarkable, since the pretreatments (particularly in CD, RL and SDS) effectively solubilized organic matter (Fig. 1), and hence increased the readily degradable organics concentration in the digester, hereby accelerating the hydrolysis and acidification steps. 
A

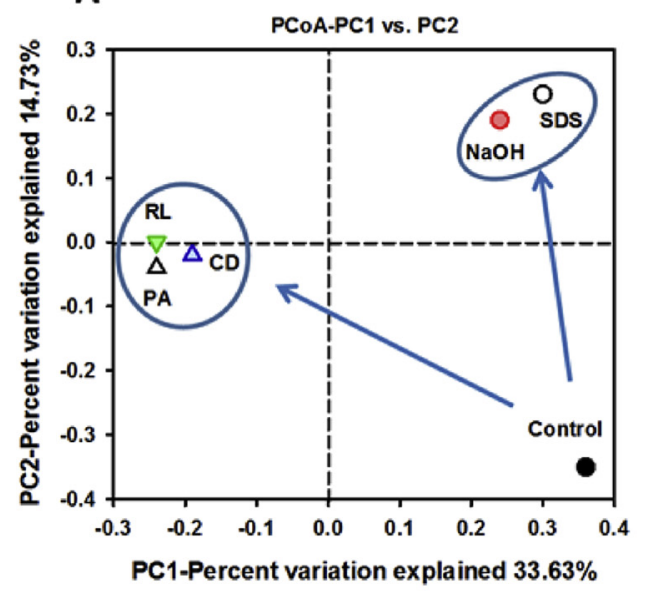

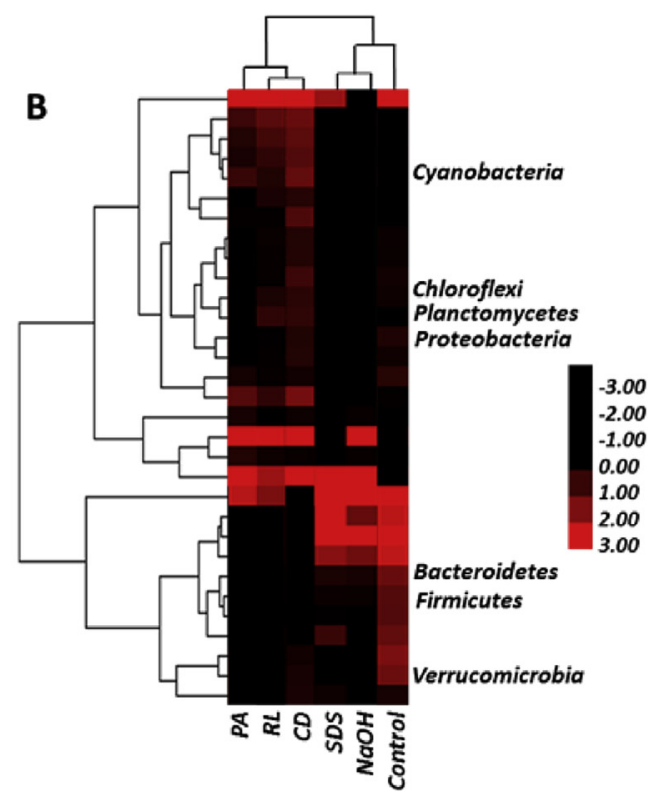

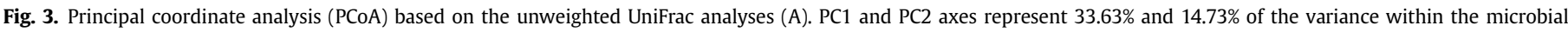

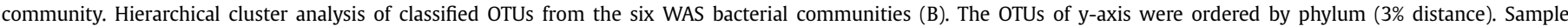

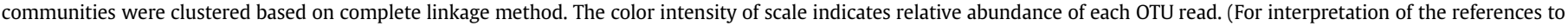
colour in this figure legend, the reader is referred to the web version of this article.)

The reason behind this maybe that all the chemicals were all onetime dosing to WAS digestion system. PA and $\mathrm{NaOH}$ was easily degraded into HAc and water during the first 3 days. However, the other three chemicals (CD, RL and SDS) were more stable, which constantly affected the efficiencies of WAS solubilization and digestion. The sustainable supply of feedstock was beneficial for the improvement of WAS digestibility. Further explanation could be presumably found in the adaptation of the sludge microorganisms, which originated from the same WWTPs. Microorganisms need to adapt to the new conditions of the pretreated sludge, characterized by a high content of soluble organic matter and VFAs, besides the presence of chemicals. However, this explanation is less plausible for the PA test, since a reaction time of $24 \mathrm{~h}$ was kept to ensure that all peroxides were eliminated from the subsequent digestion.

\subsection{Overall analysis of Illumina sequence data}

Six 16S rRNA gene libraries were constructed from MiSeq sequencing, with in total 204083 of high-quality reads (average length of $455 \mathrm{bp}$ ), subsequently clustered into 56568 OTUs at a 3\% distance (Table S1). The archaeal sequences accounted for only a small portion (4.2\%) of total sequences obtained. Rarefaction curves for all libraries displayed shapes indicative of effective sampling of community diversity, however, new bacterial phylotypes continued to emerge even after 30000 reads sampling with pyrosequencing (Fig. S5). The microbial diversities of the evolving communities were assessed based on $\alpha$-diversity. Shannon diversity index provided the species evenness. The Control showed the highest diversity (Shannon 7.76) among the six communities. Based on the ACE and Chao1 indices, indicating the richness, the Control also had relatively higher diversity (53308 and 29116), while a reduction in bacterial diversity occurred after chemical pretreatments (Table S1). The reason behind here may be that the directional selection of bacteria was caused by introducing chemicals in the WAS digestion system. That is, the proportions of functional microorganisms involved in the hydrolysis and acidification processes were higher, which resulted in the elevated organics solubilization and hydrolytic enzyme activity.

Beta diversity was calculated and used to examine the similarity of the microbiomes between the six WAS samples. Differences in the bacterial community composition among the samples were assessed by PCoA, generated from unweighted UniFrac (Fig. 3A). Principal components 1 and 2 explained 33.6\% and $14.7 \%$ of the bacterial community composition variations, respectively. It was evident that there were three groups (Fig. 3A). The control was separated from the other groups, which indicated that pretreatment significantly changed the bacterial community composition. SDS and $\mathrm{NaOH}$ samples clustered together, but were dissimilar from each other. Relatively similar communities occurred in the group PA, RL and CD. This was further proven by the results of hierarchical cluster analysis (HCA) (Fig. 3B). In other words, different chemical treatments substantially changed bacterial community structure, despite the fact that the same initial source of microbial consortia was shared.

In order to elucidate the interactions among all the OTUs and analyze the shared and most abundant OTUs in the six WAS samples, three OTU networks were constructed (Fig. 4A). Collectively, only 548 phylum-level OTUs (1.0\% of the total OTUs) were shared by all six communities (Fig. 4B). The majority of the shared OTUs were Firmicutes (36.1\%), Proteobacteria (33.6\%) and Bacteroidetes (17.0\%). For the groups I (PA, RL and CD) and II (SDS, NaOH and Control), 2483 and 1975 OTUs (4.4\% and 3.5\% of the total OTUs) were shared, the majority of which were the same, however, their distribution was quite different: Firmicutes (23.5\% versus 46.9\%), Proteobacteria (45.0\% versus $17.1 \%$ ) and Bacteroidetes (15.1\% versus $19.8 \%$ ). This was in agreement with the results of PCoA and HCA.

\subsection{Microbial diversity and distribution analysis}

To further investigate the diversity of microbial community, phylogenetic analysis of the 16S rRNA gene sequences was performed in phylum, class and genus level. Clear changes were observed in microbial community structure, after different chemical pretreatments (Fig. 4C and D). Bacteroidetes, Firmicutes and 

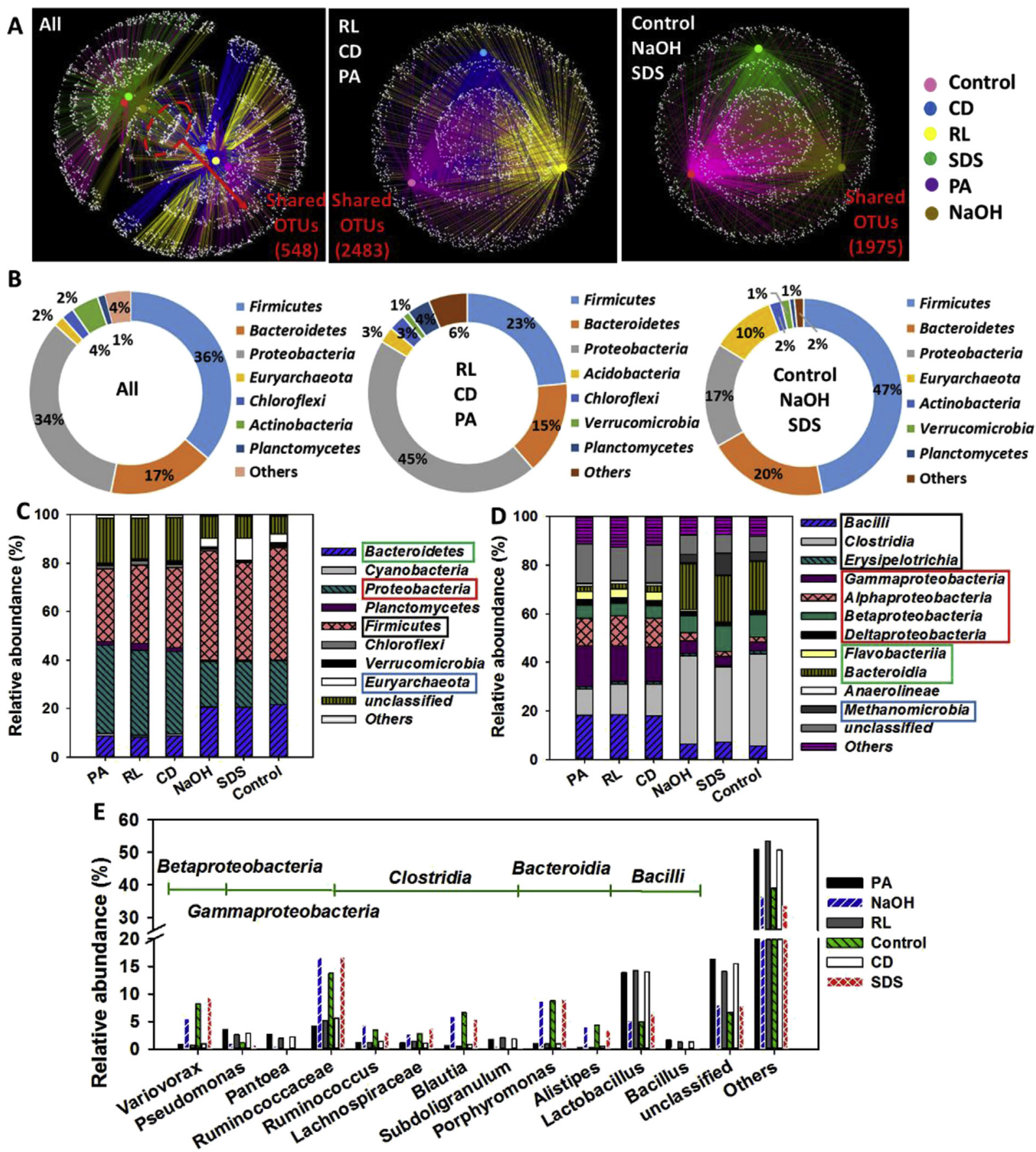

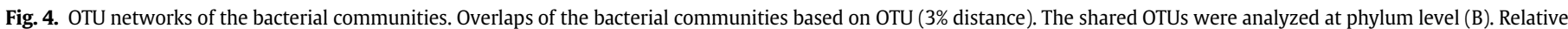

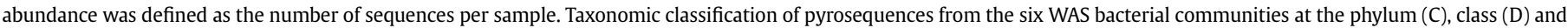
genus (E) levels.

Proteobacteria were the dominant phylum for all six communities (accounting for $75.6 \pm 0.3 \%$ (group I) and $~ 83.3 \pm 3.3 \%$ (group II) of the total bacterial sequences) (Fig. 4C), which was also the prevalence of bacterial phylum in conventional WAS anaerobic digesters $[35,36]$. Among these five pretreatments, the abundance of the three phyla in SDS and $\mathrm{NaOH}$ was very close to that in the Control $(20.9 \pm 0.6 \%, 44.0 \pm 0.5 \%$ and $18.4 \pm 3.2 \%)$. In contrast, microorganisms mainly belonging to Bacteroidetes and Firmicutes decreased in relative abundance after group I pretreatments $(8.5 \pm 0.3 \%$ and $31.7 \pm 1.5 \%)$, suggesting that these phyla were not adapted to counteract and survive in these conditions. The opposite trend was observed for Proteobacteria in group I (35.3 $\pm 1.2 \%)$. The reason for this clear distinction was that Proteobacteria is a Gram-negative group, while Firmicutes belong to a Low G + C group of Grampositive bacteria [37]. Hayes et al. (2011) showed that over-high VFA level had a strong inhibition to Gram-positive bacteria [38]. VFAs accumulation in CD and RL would certainly result in inactivation of Firmicutes (Fig. 2A). Regarding the Archaeal communities (Euryarchaeota), a shift in abundance was consistently significant between groups I and II $(0.2 \pm 0.1 \%$ versus $5.4 \pm 3.2 \%)$, especially for RL $(0.1 \%)$ and SDS (9.1\%) pretreatments. Such a huge difference of distributions of phylum between two groups should be responsible 
Table 2

Genus level identification of the Archaeal sequences (Unit: Number of OTUs). ${ }^{a}$

\begin{tabular}{lllllll}
\hline & $\mathrm{CD}$ & $\mathrm{NaOH}$ & $\mathrm{PA}$ & $\mathrm{RL}$ & $\mathrm{SDS}$ & Control \\
\hline Methanoregula & 2 & 135 & 1 & 1 & 417 & 151 \\
Methanolinea & 2 & 118 & - & 2 & 365 & 168 \\
Methanospirillum & - & 26 & - & 1 & 87 & 29 \\
Methanobacterium & 1 & 2 & - & 1 & 16 & 6 \\
Methanobrevibacter & 6 & - & 5 & 3 & - & - \\
Methanosaeta & 61 & 234 & 31 & 1 & 655 & 285 \\
\hline
\end{tabular}

a “-” representing a relative abundance less than $0.5 \%$.

for the distinct effects of chemical pretreatments on WAS digestion.

On the class level, the majority of sequences belonged to 11 classes, among which $\alpha$-proteobacteria and $\gamma$-proteobacteria (phylum Proteobacteria), Clostridia (phylum Firmicutes), Bacilli (phylum Firmicutes) and Bacteroidia (phylum Bacteroidetes) were the dominant ones, accounting for $59.7 \pm 0.3 \%$ (group I) and $67.3 \pm 4.0 \%$ (group II) of the total bacterial sequences (Fig. 4D). $\alpha-$ proteobacteria, which are known to be responsible for the utilization of carbohydrate and production of $\mathrm{HBu}$ [39], were higher (in relative abundance) in group I (11.8 $\pm 0.5 \%)$, and were found to be

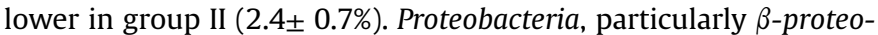
bacteria and $\gamma$-proteobacteria, are often considered r-strategists and should dominate when nutrients are plentiful [40]; they both displayed significant shifts in abundance as a function of pretreatments (Fig. 4D). Clostridia is a versatile class, made of strict anaerobes, which represent one of the most prevalent bacterial groups in biogas reactors [41]. It is possible that Clostridia, originated from the raw WAS, were enriched during anaerobic digestion, since they are spore-forming bacteria [42] and were all greatly enhanced in the presence of SDS and $\mathrm{NaOH}$ (30.9\% and 36.4\% versus $12.2 \pm 1.2 \%$ in group I).

Further investigation on the genus level provided more detailed information about microbial communities (Fig. 4E). Variovorax, which is known as D-amidase producers, could hydrolyzed amino acid into amides as well as carboxamides and 2-hydroxy acid amides [43], took up the largest proportion in group II, especially in SDS (9.4\%). The genus Pseudomonas and Pantoea (belonging to the class $\gamma$-proteobacteria), which can metabolize glucose to VFAs and hydrogen during anaerobic treatment [35], were mainly detected in group I (2.6-3.5\% and 2.0-2.7\%) and peaked in PA. Four genera of Clostridia (Ruminococcaceae, Ruminococcus, Lachnospiraceae, Blautia and Subdoligranulum) were identified, with Ruminococcaceae being the most abundant. The latter, which was mainly detected in SDS and $\mathrm{NaOH}$ (16.7\% and 16.5\%), seems to be able to decompose gallate (demethoxylated product) into acetate and $\mathrm{H}_{2} / \mathrm{CO}_{2}$ [44]. Moreover, it was also described as a facultative anaerobic carbohydratedegrading genera, able to ferment glycerol mainly to $\mathrm{H}_{2}$, succinate and acetate [45]. Besides Ruminococcus, other phylotypes affiliated with it, such as Lachnospiraceae and Blautia, prevailed in group II. Some studies showed that these genera were often accompanied by the formation of caproic and acetic acids, and a high gas production rate [46]. Nevertheless, differently from other Clostridia, Subdoligranulum was predominant in group I (1.8-2.1\%) and proportionally reflected in group II $(0.1-0.5 \%)$. As we known, the genus Porphyromonas and Alistipes belong to class Bacteroidia. Members of the Porphyromonas, which were dominant in group II as well, are known to produce various VFAs from carbohydrates or proteins [47]. The other dominant genus in group I were Lactobacillus (13.9-14.1\%) and Bacillus (1.3-1.6\%) (Firmicutes), versus $5.0-6.4 \%$ and $0.1-0.3 \%$ found in group II. It is reported in literature that Lactobacillus is specialized in monosaccharide utilization and is therefore capable of outcompeting other genera, growing on this substrate. Moreover, the genus shows a high acid tolerance, surviving at pH values of 5 and even lower. Therefore, Lactobacillus species have a selective advantage over other more acid-sensitive bacteria [46]. Bacillus is represented by spore-forming bacteria, with industrially robust dark-fermentative hydrogen-producing organisms [48]. Overall, looking at the taxa closely related to the OTUs found, it appears that the community was dominated by microorganisms that anaerobically hydrolyze complex WAS organics to acids, (in group I) and to biogas (in group II).

This was also further corroborated by the abundance of methanogen genera (Table 2). Group II was dominated by Archaea belonging to the genus Methanosaeta, accounting for $42.5-45.4 \%$ of the total archaeal sequences. A significant amount of Methanoregula (23.6-27.1\%) and Methanolinea (22.9-23.7\%) was detected, together with less frequent genera, such as Methanospirillum, Methanobacterium and Methanobrevibacter. On the contrary, CD and PA (group I) were characterized by substantially smaller amounts of Methanosaeta, with a total OTUs number of 61 and 31, and little amounts of other Archaea genera; in addition, Archaea were barely observed in RL.

\subsection{Correlation between environmental variables and microbial populations}

To better understand the roles and importance of individual groups of microbes in different chemical-pretreated WAS digestion processes, plausible relationship between characteristic genera and the environmental/performance measurements, such as $\mathrm{pH}$, methane production, hydrolytic enzymes ( $\alpha$-glucosidase and protease), VFA, soluble proteins and carbohydrates concentrations, was evaluated using CCA (Fig. 5). Based on the assumption that the WAS digestion process is most likely driven by predominant bacteria, we performed CCA analysis using 12 characteristic bacterial and 6 Archaeal genera. The results were expected to provide valuable insight about how and why different chemical pretreatments could influence the WAS hydrolysis, acidification and methogenesis efficiencies. The contents of soluble carbohydrates, proteins, VFAs, aglucosidase and protease were positively correlated with the first canonical axis (explaining $86.0 \%$ of the variance of genera distribution), while the contents of methane and $\mathrm{pH}$ showed negative interrelations. For axis 2 (which explained $9.8 \%$ variance), only the $\mathrm{pH}$ content showed good negative correlation. The detailed information is shown Table S2. The length of an arrow-line indicates the strength of the relationship between the environmental variable and the microbial community. As indicated, methane production was strongly linked to the microbial community, according to the length of the vector. Besides, it was found that $\mathrm{pH}$ was related to methane production, which was consistent with the discussions above (Section 3.2). As already stated, the $\mathrm{pH}$ values of $\mathrm{CD}$, PA and RL tests (group I) on the 10th day were all indeed beyond the optimum range, conversely, it was in the optimum range in the case of $\mathrm{NaOH}$ and the Control. Interestingly, the pyrosequencing result in SDS somewhat conflicted with the observations of methane production. In fact, despite the relative abundance of Archaea genera was remarkably higher in the case of SDS, the methane yield was comparatively lower than that in $\mathrm{NaOH}$ and Control. The reason may be that methanogens were only inhibited (in their metabolic activity), but not inactivated. CCA further showed that $\mathrm{pH}$ and methane production had a positive correlation with some bacterial genera (Fig. 5), including Variovorax, Porphyromonadaceae, Alistipes, Blautia, Ruminococcus, Ruminococcaceae and Lachnospiraceae, which were all abundant in group II. Moreover, most Archaea genera were also found to be significantly correlated to the variables of $\mathrm{pH}$ and methane production, such as Methanoregula, Methanospirillum, Methanolinea, Methanobacterium and Methanosaeta. The changes of hydrolytic enzymes ( $\alpha$-glucosidase and 


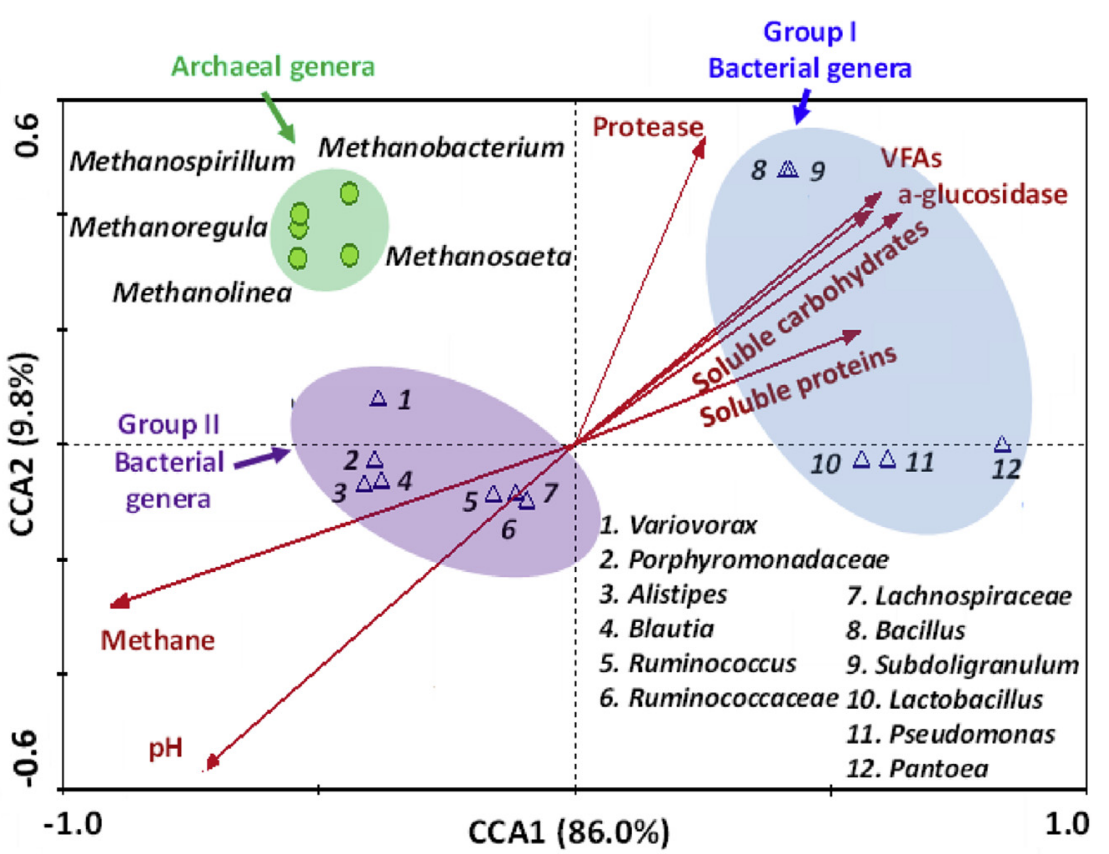

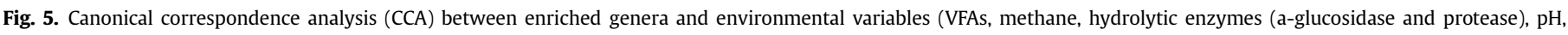
soluble proteins and carbohydrates).

protease), soluble proteins and carbohydrates concentrations were associated to VFA production, indicating that they might play an important role in WAS hydrolysis and acidification processes. $\mathrm{Ba}$ cillus and Subdoligranulum were highly correlated with hydrolytic enzymes, soluble carbohydrates and VFAs production, followed by Pantoea, Pseudomonas and Lactobacillus. It is worthwhile to note that Pantoea was comparatively correlated with soluble proteins concentration. Previous studies have proven that Pantoea was also capable of producing bacterial mycolytic enzymes, such as chitinases, proteases, and glucanase [49], which could be beneficial for cell lysis and subsequent intracellular organics (mainly proteins) hydrolysis. Conversely, these five bacterial genera were all abundant in group I. In this sense, the CCA results suggested that chemical pretreatments may play an important role in structuring the indigenous microbial community in WAS, thus confirming that the relationship between community structure and the measured variables may reveal precious insight into the WAS digestion process.

\subsection{Significance of chemical WAS pretreatments and potential implementation for WWTPS}

This study has, for the first time, shed light on how and why the different chemical pretreatments, including alkaline, solubilizer, peroxide, chemical and biological surfactants, could enhance the WAS digestion efficiency, by means of process assessment associated to microbial community response analysis. More importantly, the finding obtained in this study might have crucial implications for the operation of WWTPs. Fig. 6 illustrates an enhanced "carbon source recovery - nutrient removal - energy recovery" concept with the typical chemical pretreated WAS digestion applied in a WWTP. It is known that, in order to promote growth of denitrifying bacteria and phosphorus accumulating organisms (PAOs) over competing organisms, a mix of HAc and HPr is required. In this study, we found that the solubilizer (CD) and surfactants treatment (RL and SDS) led to an evident increase in VFAs yield. Nevertheless, the ratio of HAc/ $\mathrm{HPr}$ was quite diverse. Chen and colleagues found that the phosphorus removal efficiency was significantly increased with the decrease of HPr/HAc [50]. Paul and coworkers observed that the denitrification capacity per mole of carbon differed in the order sucrose $<$ glucose $<\operatorname{HAc}<\operatorname{HPr}[51]$. Among these pretreatments, HPr concentration maximized in CD (1499 $\mathrm{mg} \mathrm{COD} / \mathrm{L})$, followed the $\mathrm{RL}$ (769 mg COD/L) treatments. It is also worth noting that, when using WAS as external carbon source in a WWTP, the VFAs production should be maximized, while, on the other hand, the input should be minimized. From this perspective, RL would have a big advantage since, unlike other pretreatment methods, it is a renewable chemical that could be in situ generated during the WAS digestion, thus representing a feasible and practical technology [6].

Besides, mixtures of acids, as produced in this work, can also be used to obtain co-polymers with different monomer compositions. Being recognized as good candidates for biodegradable plastics, PHAs are completely biodegradable and exhibit properties similar to conventional thermoplastics. Taking HAc and HPr as sole substrate, respectively, 98\% 3-hydroxybutyrate $(3 \mathrm{HB})+2 \% 3-$ hydroxyvalerate (3HV) and 7\% 3HB + 83\% 3HV + 10\% 3-hydroxy2-methylvalerate (3H2MV) was gained [16]. The technical feasibility of producing PHAs from sludge fermentation liquid has been demonstrated [16,52]. HAc/HPr varied from 1:1 (CD and RL) to 2:1 (SDS) and 3:1 (PA) were obtained in this study. Due to consideration of input economy, RL and PA could be suitable for the tailored synthesis of biopolymers with given target properties of more $3 \mathrm{HB}$ or $3 \mathrm{HV}$.

In addition, WAS contains a significant amount of embedded energy, in the order of $20 \mathrm{MJ} / \mathrm{kg}$ of dry sludge. By reducing the embedded energy and practicing energy recovery from WAS, it has been estimated that WWTP could be energy producers. More methane was produced in the $\mathrm{NaOH}$ pretreatment than in the others, but slightly less than in the control. There were mainly two reasons: (1) we only tested the methane yield on day 10 , which was relatively shorter for methanogenesis; (2) the alkaline pretreatment was only in the initial phase, but not maintained during a period of time, (soluble organics for subsequent acidification and methanogenesis was insufficient). Zhang et al. [4] demonstrated 


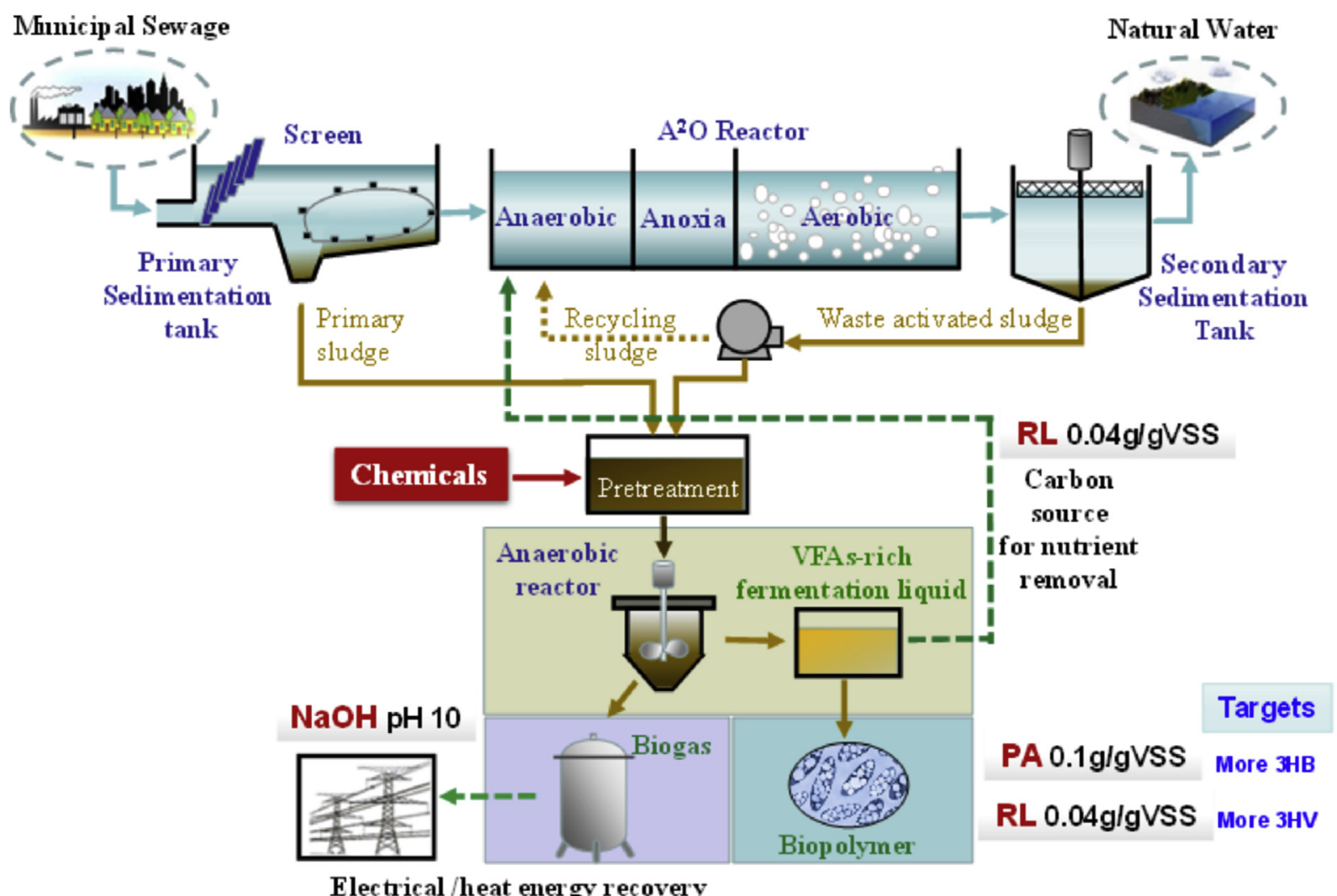

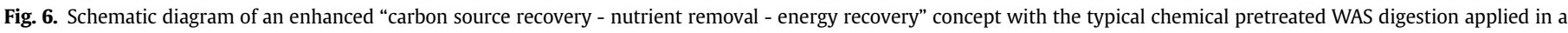
WWTP.

that controlled alkaline ( $\mathrm{pH} 10$ for $8 \mathrm{~d}$ ) pretreated sludge showed higher cumulative methane yield, which was even 3.5-, 3.1-, and 2.3-fold that of the ultrasonic, thermal, and thermal-alkaline pretreated sludge, respectively [4]. Thus, the proposed concept in Fig. 6 may be a practical way to reduce sludge production and gain energy and high value-added products simultaneously in WWTPs.

Basically, chemical pretreatment is economically unattractive for anaerobic digestion due to its high costs, to find out whether the selected three chemicals (PA, NaOH and RL) can be attempted in a perspective of industry is meaningful. PA is sold as an aqueous quaternary equilibrium mixture of HAc and hydrogen peroxide [31], the raw materials are all basic chemicals and relatively easily acquired. Besides, there is no toxic products (water and HAc) formed during its degradation. Alkaline has been selected as a potential way for improving biogas production from WAS digestion, which is regarded as a cost-effective and operation-convenient chemical pretreatment. RL, as a kind of biosurfactants, is a renewable and eco-friendly chemical that could be in situ generated during the VFAs production from WAS, which makes it a desirable replacement of traditionally chemical surfactants [6]. The findings obtained in this work may provide a scientific basis for the application of chemical pretreatments for WAS treatment. Certainly, the assessment should further include due considerations of the practical challenges associated with management for WWTPs. Moreover, ultimately processes must be systematically developed in conjunction with life-cycle, economic, and human health based assessments, as a framework for ensuring sustainability.

\section{Conclusions}

This study observed the effects of typical chemical pretreatments: solubilizer, alkaline, peroxide, biological and chemical surfactants on WAS digestion, including solubilization, hydrolysis, acidification and methanogenesis, and suggested crucial implications for the operation of WWTPs. Solubilizer (CD) and surfactants (RL and SDS) were more beneficial to WAS solubilization, hydrolysis and acidification. Likewise, methane production was strongly pretreatment-dependent, and was clearly inhibited by $C D$, peroxide $(P A)$ and RL treatments. A comprehensive study to shed light on the underlying mechanism of enhanced WAS digestion under different chemical pretreatments was undertaken for the first time, by means of process assessment associated to microbial community response analysis. Moreover, the findings obtained in this study might have crucial implications for the operation of WWTPs.

\section{Acknowledgements}

This research was supported by National Natural Science Foundation of China (NSFC, No. 51608345, 51378330 and 51408396), by State Key Laboratory Breeding Base of Coal Science and Technology Co-founded by Shanxi Province and the Ministry of Science and Technology, Taiyuan University of Technology (No: MKX201504), by China Postdoctoral Science Foundation (No. 2015M570241 and 2016M591416), by the Key Research and Development (R\&D) Project of Shanxi Province (No. 201603D321012) and the International Science and Technology Cooperation Project of Shanxi Province (2014081007-1). The authors gratefully acknowledge Victex Company, China for providing the rhamnolipid solution. They would also like to thank the reviewers for positive criticism to improve the quality of the manuscript. 


\section{Appendix A. Supplementary data}

Supplementary data related to this article can be found at http:// dx.doi.org/10.1016/j.energy.2017.02.166.

\section{References}

[1] Wu L-J, Qin Y, Hojo T, Li Y-Y. Upgrading of anaerobic digestion of waste activated sludge by temperature-phased process with recycle. Energy 2015;87:381-9.

[2] Appels L, Baeyens J, Degrève J, Dewil R. Principles and potential of the anaerobic digestion of waste-activated sludge. Prog Energ Combust 2008;34(6):755-81.

[3] Yuan H, Chen Y, Zhang H, Jiang S, Zhou Q, Gu G. Improved bioproduction of short-chain fatty acids (SCFAs) from excess sludge under alkaline conditions. Environ Sci Technol 2006;40(6):2025-9.

[4] Zhang D, Chen Y, Zhao Y, Zhu X. New sludge pretreatment method to improve methane production in waste activated sludge digestion. Environ Sci Techno 2010;44(12):4802-8.

[5] Jiang S, Chen Y, Zhou Q. Effect of sodium dodecyl sulfate on waste activated sludge hydrolysis and acidification. Chem Eng J 2007;132(1-3):311-7.

[6] Zhou A, Yang C, Guo Z, Hou Y, Liu W, Wang A. Volatile fatty acids accumulation and rhamnolipid generation in situ from waste activated sludge fermentation stimulated by external rhamnolipid addition. Biochem Eng J 2013;77:240-5.

[7] Zhou A, Luo H, Varrone C, Wang Y, Liu W, Wang A, et al. Enhanced anaerobic digestibility of waste activated sludge by plant-derived biosurfactant. Process Biochem 2015;50(9):1413-21.

[8] Yang X, Du M, Lee D-J, Wan C, Zheng L, Li G, et al. Enhanced production of volatile fatty acids (VFAs) from sewage sludge by $\beta$-cyclodextrin. Bioresour Technol 2012;110:688-91.

[9] Mokhayeri Y, Riffat R, Murthy S, Bailey W, Takacs I, Bott C. Balancing yield, kinetics and cost for three external carbon sources used for suspended growth post-denitrification. Water Sci Technol 2009;60(10).

[10] Zubrowska-Sudol M, Walczak J. Enhancing combined biological nitrogen and phosphorus removal from wastewater by applying mechanically disintegrated excess sludge. Water Res 2015;76:10-8.

[11] Soares A, Kampas P, Maillard S, Wood E, Brigg J, Tillotson M, et al. Comparison between disintegrated and fermented sewage sludge for production of a carbon source suitable for biological nutrient removal. J Hazard Mater 2010;175(1):733-9.

[12] Ji Z, Chen Y. Using sludge fermentation liquid to improve wastewater shortcut nitrification-denitrification and denitrifying phosphorus removal via nitrite. Environ Sci Technol 2010;44(23):8957-63.

[13] Liu W, Cai W, Guo Z, Wang L, Yang C, Varrone C, et al. Microbial electrolysis contribution to anaerobic digestion of waste activated sludge, leading to accelerated methane production. Renew Energy 2016;91:334-9.

[14] Cai W, Han T, Guo Z, Varrone C, Wang A, Liu W. Methane production enhancement by an independent cathode in integrated anaerobic reactor with microbial electrolysis. Bioresour Technol 2016;208:13-8.

[15] Liu W, He Z, Yang C, Zhou A, Guo Z, Liang B, et al. Microbial network for waste activated sludge cascade utilization in an integrated system of microbial electrolysis and anaerobic fermentation. Biotechnol Biofuel 2016;9(1).

[16] Jiang Y, Chen Y, Zheng X. Efficient polyhydroxyalkanoates production from a waste-activated sludge alkaline fermentation liquid by activated sludge submitted to the aerobic feeding and discharge process. Environ Sci Techno 2009;43(20):7734-41.

[17] Cadoret A, Conrad A, Block J-C. Availability of low and high molecular weight substrates to extracellular enzymes in whole and dispersed activated sludges. Enzyme Microb Technol 2002;31(1-2):179-86.

[18] Sheng GP, Yu HQ. Characterization of extracellular polymeric substances of aerobic and anaerobic sludge using three-dimensional excitation and emission matrix fluorescence spectroscopy. Water Res 2006;40(6):1233-9.

[19] Liu W, Wang A, Cheng S, Logan BE, Yu H, Deng Ye, et al. Geochip-based functional gene analysis of anodophilic communities in microbial electrolysis cells under different operational modes. Environ Sci Technol 2010;44(19): 7729-35.

[20] Zhou J, Liu W, Deng Y, Jiang YH, Xue K, He Z, et al. Stochastic assembly leads to alternative communities with distinct functions in a bioreactor microbial community. MBio 2013;4(2).

[21] Guo Z, Zhou A, Yang C, Liang B, Sangeetha T, He Z, et al. Enhanced short chain fatty acids production from waste activated sludge conditioning with typical agricultural residues: carbon source composition regulates community functions. Biotechnol Biofuel 2015;8:192.

[22] Lozupone C, Knight R. UniFrac: a new phylogenetic method for comparing microbial communities. Appl Environ Microbiol 2005;71(12):8228-35.

[23] Shannon P, Markiel A, Ozier O, Baliga NS, Wang JT, Ramage D, et al. Cytoscape: a software environment for integrated models of biomolecular interaction networks. Genome Res 2003;13:2498-504.

[24] Eaton A, Clesceri LS, Rice EW, Greenberg AE, Franson M. APHA: standard methods for the examination of water and wastewater. Washington, DC: Centennial Edition, APHA, AWWA, WEF; 2005.

[25] Goel R, Mino T, Satoh H, Matsuo T. Enzyme activities under anaerobic and aerobic conditions in activated sludge sequencing batch reactor. Water Res
$1998 ; 32(7): 2081-8$

[26] Wang Z, Wu Z, Tang S. Characterization of dissolved organic matter in a submerged membrane bioreactor by using three-dimensional excitation and emission matrix fluorescence spectroscopy. Water Res 2009;43(6):1533-40.

[27] Li WH, Sheng GP, Liu XW, Yu HQ. Characterizing the extracellular and intracellular fluorescent products of activated sludge in a sequencing batch reactor. Water Res 2008;42(12):3173-81.

[28] Luo K, Yang Q Li XM, Chen HB, Liu X, Yang GJ, et al. Novel insights into enzymatic-enhanced anaerobic digestion of waste activated sludge by threedimensional excitation and emission matrix fluorescence spectroscopy. Chemosphere 2013;91(5):579-85.

[29] Zhang Y, Zhang P, Guo J, Ma W, Xiao L. Spectroscopic analysis and biodegradation potential study of dissolved organic matters in sewage sludge treated with high-pressure homogenization. Bioresour Technol 2013;135:616-21.

[30] Zhao J, Wang D, Li X, Yang Q, Chen H, Zhong Y, et al. Free nitrous acid serving as a pretreatment method for alkaline fermentation to enhance short-chain fatty acid production from waste activated sludge. Water Res 2015;78: $111-20$.

[31] Appels L, Van Assche A, Willems K, Degreve J, Van Impe J, Dewil R. Peracetic acid oxidation as an alternative pre-treatment for the anaerobic digestion of waste activated sludge. Bioresour Technol 2011;102(5):4124-30.

[32] Wang Q, Kuninobu M, Ogawa HI, Kato Y. Degradation of volatile fatty acids in highly efficient anaerobic digestion. Biomass Bioenergy 1999;16(6):407-16.

[33] Huang X, Shen C, Liu J, Lu L. Improved volatile fatty acid production during waste activated sludge anaerobic fermentation by different bio-surfactants. Chem Eng J 2015;264:280-90.

[34] Turovskiy IS, Mathai P. Wastewater sludge processing. John Wiley \& Sons; 2006.

[35] Zhou A, Liu W, Varrone C, Wang Y, Wang A, Yue X. Evaluation of surfactants on waste activated sludge fermentation by pyrosequencing analysis. Bioresour Technol 2015;192:835-40.

[36] Sun R, Zhou A, Jia J, Liang Q, Liu Q, Xing D, et al. Characterization of methane production and microbial community shifts during waste activated sludge degradation in microbial electrolysis cells. Bioresour Technol 2014;175C: 68-74.

[37] Piterina AV, Bartlett J, Pembroke JT. Phylogenetic analysis of the bacterial community in a full scale autothermal thermophilic aerobic digester (ATAD) treating mixed domestic wastewater sludge for land spread. Water Res 2012;46(8):2488-504.

[38] Hayes D, Izzard L, Seviour R. Microbial ecology of autothermal thermophilic aerobic digester (ATAD) systems for treating waste activated sludge. Syst Appl Microbiol 2011;34(2):127-38.

[39] Lenin Babu M, Venkata Subhash G, Sarma P, Venkata Mohan S. Bio-electrolytic conversion of acidogenic effluents to biohydrogen: an integration strategy for higher substrate conversion and product recovery. Bioresour Technol 2013;133:322-31.

[40] Van Elsas J, Torsvik V, Hartmann A, Øvreås L, Jansson J. The bacteria and Archaea in Soil. Modern Soil microbiology. second ed. United States: CRC; 2007.

[41] Luo G, Angelidaki I. Analysis of bacterial communities and bacterial pathogens in a biogas plant by the combination of ethidium monoazide, PCR and Ion Torrent sequencing. Water Res 2014;60:156-63.

[42] Teixeira LC, Peixoto RS, Cury JC, Sul WJ, Pellizari VH, Tiedje J, et al. Bacterial diversity in rhizosphere soil from Antarctic vascular plants of Admiralty Bay, maritime Antarctica. ISME J 2010;4(8):989-1001.

[43] Krieg L, Ansorge-Schumacher MB, Kula MR. Screening for amidases: isolation and characterization of a novel D-amidase from Variovorax paradoxus. Adv Synth Catal 2002;344(9):965-73.

[44] Kato S, Chino K, Kamimura N, Masai E, Yumoto I, Kamagata Y. Methanogenic degradation of lignin-derived monoaromatic compounds by microbial enrichments from rice paddy field soil. Sci Rep 2015;5:14295.

[45] van Gelder AH, Sousa DZ, Rijpstra WIC, Damsté JSS, Stams AJ, SánchezAndrea I. Ercella succinigenes gen. nov., sp. nov., an anaerobic succinateproducing bacterium. Int J Syst Evol Microbiol 2014;64(Pt 7):2449-54.

[46] Sträuber H, Schröder M, Kleinsteuber S. Metabolic and microbial community dynamics during the hydrolytic and acidogenic fermentation in a leach-bed process. Energy, Sustain Soc 2012;2(1):1-10.

[47] Ziganshin AM, Schmidt T, Scholwin F, Il'inskaya ON, Harms H, Kleinsteuber S. Bacteria and archaea involved in anaerobic digestion of distillers grains with solubles. Appl Microbiol Biotechnol 2011;89(6):2039-52.

[48] Kumar P, Patel SK, Lee J-K, Kalia VC. Extending the limits of Bacillus for novel biotechnological applications. Biotechnol Adv 2013;31(8):1543-61.

[49] Gohel V, Maisuria V, Chhatpar H. Utilization of various chitinous sources for production of mycolytic enzymes by Pantoea dispersa in bench-top fermenter. Enzyme Microb Technol 2007;40(6):1608-14.

[50] Chen Y, Randall AA, McCue T. The efficiency of enhanced biological phosphorus removal from real wastewater affected by different ratios of acetic to propionic acid. Water Res 2004;38(1):27-36.

[51] Paul J, Beauchamp E, Trevors J. Acetate, propionate, butyrate, glucose, and sucrose as carbon sources for denitrifying bacteria in soil. Can J Microbiol 1989;35(8):754-9.

[52] Frison N, Katsou E, Malamis S, Oehmen A, Fatone F. Development of a novel process integrating the treatment of sludge reject water and the production of polyhydroxyalkanoates (PHAs). Environ Sci Technol 2015;49(18):10877-85. 